\title{
Assessment of noise parameters in elements of urban transport infrastructure
}

\author{
Taisia Bolshanina ${ }^{1, *}$, and Sergei Ovsiannikov ${ }^{1}$ \\ ${ }^{1}$ Tomsk State University of Architecture and Building, 634003 Tomsk, Russia
}

\begin{abstract}
The paper considers urban road network in combination with elements of transport infrastructure which are presented as noise sources. Acoustic analysis of the level of noise produced by transport accounts only railway track spans and highways as linear sources of noise. Within the study road network elements and objects of transport infrastructure were classified; traffic interchanges and objects of transport infrastructure were presented as spatial noise source, which provides relevance of this study. The purpose of the research is development of methods for analyzing noise parameters of road networks and objects of transport infrastructure, as well as analysis of noise level in the residential territories caused by the combination of linear and spatial noise sources. The results of analysis and measurements demonstrate that evaluation of noise level caused by transport of the near-highway territory without the account of traffic interchanges as spatial noise sources leads to downward bias of noise level up to $10 \mathrm{dBA}$.
\end{abstract}

\section{Introduction}

Transport is the main source of noise in cities. Acoustic analysis while evaluating noise pollution of urban territories in Russia is performed in compliance with regulatory documents: GOST 20444-2014 [1], GOST 23337-2014 [2], SP 51.13330.2011 [3], etc. These standard documents are based on the methods for defining the noise level in residential territories developed by the following authors: G. Osipova, [4, 5], P. Pospelova $[6,7]$, A. Faktorovich [8], etc. Drawback of the existing methods for noise level evaluation consists in lack of classification of elements of urban road network and objects of transport infrastructure with regard to noise parameters. Besides, traffic interchanges and objects of transport infrastructure are not accounted as spatial noise sources, whereas the measurements show that noise parameters of urban road network cannot be presented as a combination of linear noise sources only.

The accuracy of acoustic analysis depends on the correctly defined type and number of noise sources. The method of analysis applicable either for linear noise sources or for spatial ones is selected based on these parameters. This research is aimed at developing methods for analyzing noise parameters of road networks and objects of transport

\footnotetext{
* Corresponding author: BolshaninaTS@gmail.com
} 
infrastructure, as well as analyzing noise level in the residential territories caused by the combination of linear and spatial noise sources.

\section{Methods of research}

The existing methods for evaluation of noise level in urban territories do not account objects of transport infrastructure and elements of road networks which occupy large areas. Road network elements include track spans and traffic interchanges which can be represented by intersections or multilevel transport interchanges. Elements of railway transport are single-track or double-track railway track spans, freight or passenger stations and passing loops.

Objects of transport infrastructure are represented by transport storage and maintenance facilities: parking lots, car washes, repair facilities and depot for railway transport.

According to GOST 23337-2014 [2], the following types of noise produced by transport are singled out: roadway noise, railway noise, waterborne noise and aircraft noise. Below, in Tables 1 and 2, the authors present own classification.

Table 1. Classification of urban transport and road network.

\begin{tabular}{|c|c|c|}
\hline \multirow{4}{*}{ 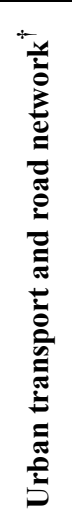 } & road network & $\begin{array}{l}\text { - track spans: residential streets; main district highways; } \\
\text { main city highways; cargo lines; } \\
\text { - traffic interchanges and junctions: intersections; traffic } \\
\text { circles; multilevel interchanges. } \\
\end{array}$ \\
\hline & railway transport & $\begin{array}{l}\text { - railway hauls: single-track; double-track; } \\
\text { stations and loops: passing loops; passenger stations; } \\
\text { freight stations. }\end{array}$ \\
\hline & $\begin{array}{l}\text { underground } \\
\text { railway and street } \\
\text { railway }\end{array}$ & $\begin{array}{l}\text { - } \quad \text { underground railway hauls; } \\
\text { - } \text { street railway hauls; } \\
\text { - } \text { open underground stations; } \\
\text { - tram stations. }\end{array}$ \\
\hline & $\begin{array}{c}\text { waterborne } \\
\text { transport }\end{array}$ & $\begin{array}{l}\text { - water ways; } \\
\text { - } \text { riverside stations; } \\
\text { - } \quad \text { cargo ports. }\end{array}$ \\
\hline
\end{tabular}

Table 2. Classification of urban transport infrastructure.

\begin{tabular}{|c|c|c|}
\hline \multirow{4}{*}{ 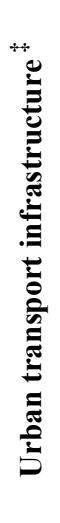 } & motor transport & $\begin{array}{l}\text { - } \text { passenger transportation companies; } \\
\text { - goods transportation companies; } \\
\text { - trolleybus fleet; } \\
\text { - } \text { specialty vehicles companies; } \\
\text { - car washes; } \\
\text { - repair facilities; } \\
\text { - tire services; } \\
\text { - car parkings. }\end{array}$ \\
\hline & railway transport & - railway depot. \\
\hline & $\begin{array}{c}\text { underground } \\
\text { railway and street } \\
\text { railway }\end{array}$ & $\begin{array}{l}\text { - underground depot; } \\
\text { - tram depot. }\end{array}$ \\
\hline & $\begin{array}{l}\text { waterborne } \\
\text { transport }\end{array}$ & - water transport repair facilities. \\
\hline
\end{tabular}

$\dagger$ without the account of air transport

$\$$ without the account of air transport 
Elements of road network and objects of transport infrastructure can be classified with regard to the noise source:

- track spans as linear noise sources;

- multilevel interchanges and transport maintenance enterprises as spatial noise sources.

Highways shall be considered as linear noise sources, and noise levels in residential territory shall be evaluated with the account of noise reduction factors [4]. With two and more highways, the levels of noise they produce are defined by energy summation.

To evaluate the impact of traffic interchanges on the acoustic mode of near-highway territories one shall define the integral value of noise level in the calculated point obtained from a combination of sources using the following method. According to Figure 1a, the calculated point is affected by noise produced by two linear sources and one spatial source represented by a traffic interchange. The noise parameters of the linear noise source were defined based on the results of measuring equivalent and maximum noise levels according to GOST 20444-2014 [1]. Sound power applied to acoustic center which is a geometrical center of the traffic interchange shall be considered a noise parameter for spatial noise source.
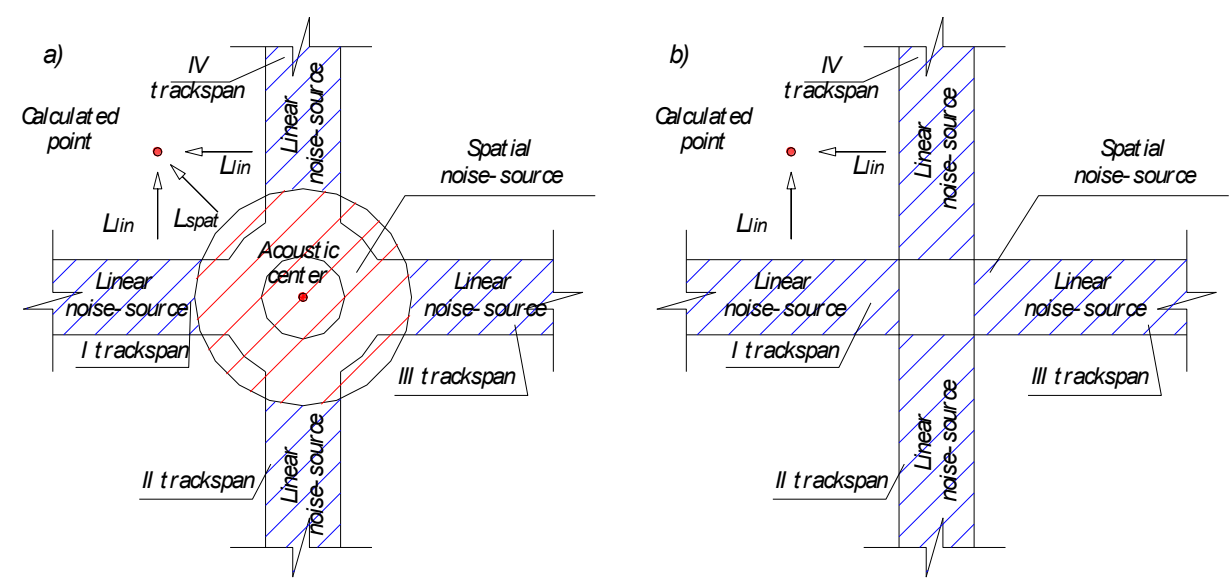

Fig. 1. Schemes of noise sources location in transport interchanges: a - single-level interchange - a combination of spatial and linear noise sources; $b$ - intersection - crossing of linear noise sources.

Below is presented the algorithm for defining noise parameters in the calculated points located in proximity to transport interchanges, with the example of a cloverleaf interchange in Tomsk city (Russia):

1. Measure the noise levels in the calculated points. Location of the calculated points is presented in Figure 2.

Let us present a cloverleaf interchange, as well as a traffic circle interchange, in the form of an ellipse-shaped spatial source, similar to the scheme in Figure 1a. The track spans of the interchange are Pushkina Street in both ways, Komsomolsky Avenue and 79 Gvardeiskoy Divisii Street (Fig. 2). At each liner section of a noise source two points are selected being 7.5 meters away from the closest axis of motion for defining the mean value of noise level produced by the linear noise source $(1,1.1,5,5.1,11,11.1,15,15.1)$. To define the noise parameter of a spatial noise source two uniform points are selected in the track spans. 


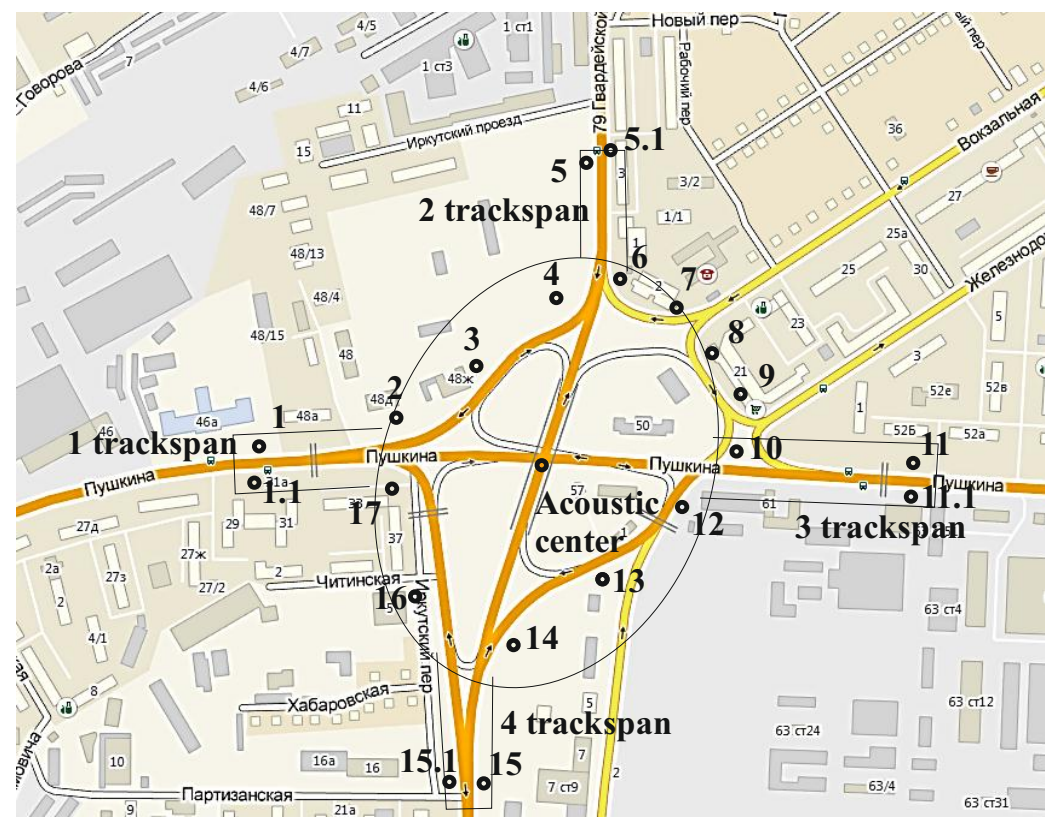

Fig. 2. The schematic map of a cloverleaf interchange with marked noise sources and calculated points.

2. Define the average noise level produced by the track spans, which is an arithmetic mean of the two measured values.

3. Find the average noise level of a spatial noise source in a cloverleaf interchange by the formula (1):

$$
\overline{L_{e q}}=10 \cdot \lg \left[\left(\frac{1}{n}\right) \sum_{i=1}^{n} 10^{0,1 \cdot L_{i}}\right], d B A
$$

where $L_{i}$ - equivalent sound level at the $i$ point, dBA; $n$ - number of $i$ points.

4. Track spans have the same traffic intensity, hence the directivity index of a nose source is defined by the formula (2):

$$
\Phi_{i}=G_{i}=L_{e q i}-\overline{L_{e q}}, \quad d B A
$$

where $L_{e q i}$ - equivalent noise level at the $i$ point, dBA.

5. Find the sound power of a spatial noise source in compliance with the "Recommendations on Measurement and Evaluation of External Noise Produced by Industrial Enterprises" by the formula (3):

$$
L_{p}=\overline{L_{e q}}+10 \cdot \log \frac{2 S}{S_{0}}, \quad d B A
$$

where $S$ - area of the territory occupied by a spatial noise source, $\mathrm{m}^{2} ; S_{0}=1 \mathrm{~m}^{2}$.

6. To perform the calculation of equivalent sound level in the territory adjacent to a traffic interchange two calculated points are selected (Fig. 2) located 2 meters away from the building facades and 1.5 meters above the road surface level. Figure 3 demonstrates the average sound levels.

7. Find the noise level in the calculated points located two meters away from the facades using the summability method of integrals (Fig. 4). 


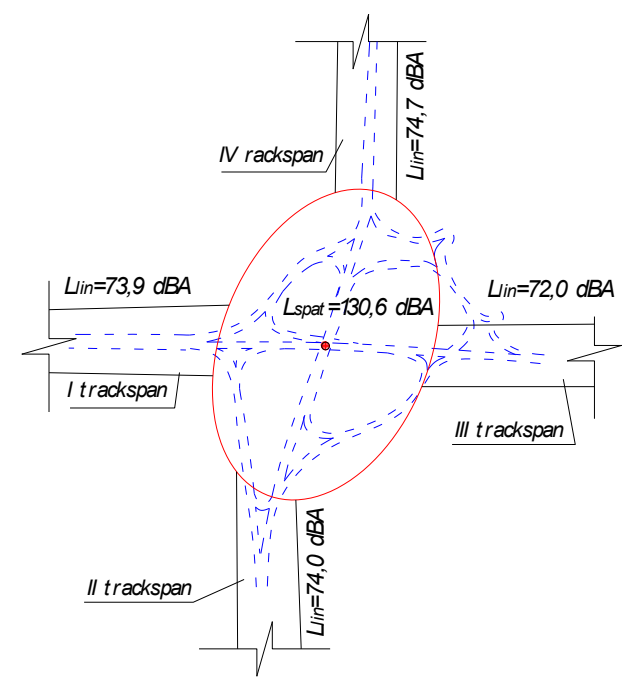

Fig. 3. Averaged parameters of noise levels (L) in the track spans of a traffic interchange.

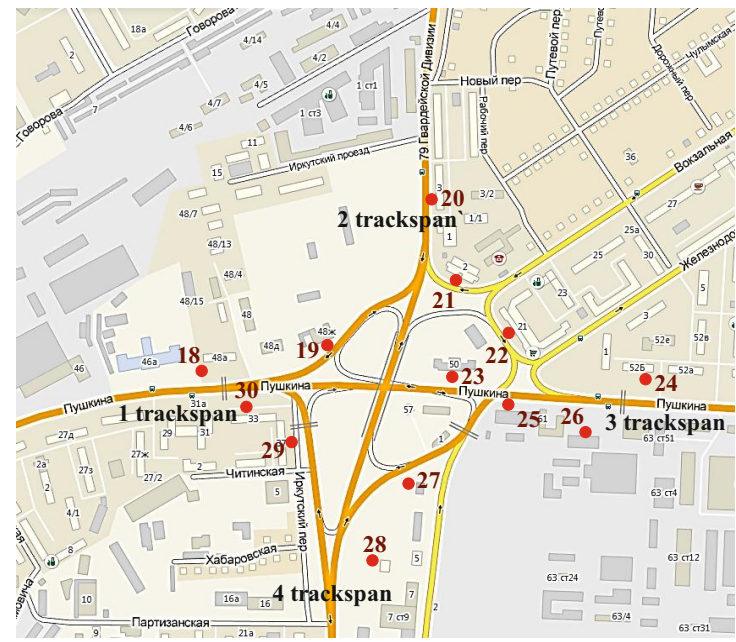

Fig. 4. Schematic map with marked calculated points in a transport interchange.

\section{Results}

The measurement results for the calculated points marked in Figure 2 are presented in Table 3. The average noise level of a spatial noise source of a cloverleaf interchange defined by the formula (1) equals $72.8 \mathrm{dBA}$.

Table 3. Measured parameters of a cloverleaf interchange (intersection of Komsomolsky Avenue and Pushkina Street) and the noise level in the calculated points.

\begin{tabular}{|c|c|c|c|c|c|c|c|}
\hline \multirow{2}{*}{$\begin{array}{c}\text { Number of } \\
\text { the calculated } \\
\text { point }\end{array}$} & \multirow{2}{*}{$\begin{array}{c}\text { Velocity } \\
\text { km/h }\end{array}$} & \multirow{2}{*}{$\begin{array}{l}\text { Intensity, } \\
\text { vehicles/h }\end{array}$} & \multicolumn{3}{|c|}{ Traffic flow composition } & \multirow{2}{*}{$\begin{array}{c}\text { Measured noise } \\
\text { level, } \\
\text { Leq / Lmax, dB }\end{array}$} & \multirow{2}{*}{$\begin{array}{c}\text { Directivity } \\
\text { index } \\
\Phi(G), \text { dBA }\end{array}$} \\
\hline & & & trucks & buses & cars & & \\
\hline 1 & $50-60$ & 4182 & 5 & 7 & 88 & $73.3 / 83.3$ & - \\
\hline 1.1 & $50-60$ & 3588 & 3 & 7 & 90 & $74.5 / 87.7$ & - \\
\hline 2 & $30-40$ & 1248 & 3 & 5 & 92 & $69.3 / 76.6$ & -3.5 \\
\hline 3 & $30-40$ & 1260 & 4 & 5 & 91 & $67.8 / 76.2$ & -5.0 \\
\hline
\end{tabular}




\begin{tabular}{|c|c|c|c|c|c|c|c|}
\hline 4 & $30-50$ & 2424 & 4 & 4 & 92 & $76.9 / 96.3$ & 4.1 \\
\hline 5 & $40-60$ & 2400 & 4 & 3 & 93 & $75.4 / 82.8$ & - \\
\hline 5.1 & $50-60$ & 2796 & 5 & 3 & 92 & $74.0 / 82.6$ & - \\
\hline 6 & $30-40$ & 648 & 13 & 2 & 85 & $63.7 / 78.5$ & -9.1 \\
\hline 7 & $30-40$ & 1122 & 5 & 3 & 92 & $63.3 / 73.6$ & -9.5 \\
\hline 8 & $30-40$ & 1050 & 6 & 5 & 89 & $66.6 / 84.6$ & -6.2 \\
\hline 9 & $30-40$ & 894 & 5 & 5 & 90 & $66.5 / 80.4$ & -6.3 \\
\hline 10 & $30-40$ & 540 & 7 & 3 & 90 & $69.4 / 87.1$ & -3.4 \\
\hline 11 & $50-60$ & 4254 & 5 & 7 & 88 & $71.4 / 79.9$ & - \\
\hline 11.1 & $50-60$ & 4182 & 5 & 6 & 89 & $72.6 / 85.7$ & - \\
\hline 12 & $30-40$ & 1056 & 5 & 3 & 92 & $73.1 / 91.2$ & 0.3 \\
\hline 13 & $40-60$ & 882 & 1 & 7 & 92 & $69.8 / 80.0$ & -3.0 \\
\hline 14 & $40-60$ & 558 & 6 & 6 & 88 & $72.4 / 87.2$ & -0.4 \\
\hline 15 & $50-60$ & 3168 & 5 & 2 & 93 & $74.2 / 83.5$ & - \\
\hline 15.1 & $50-60$ & 3348 & 5 & 3 & 92 & $73.8 / 93.1$ & - \\
\hline 16 & $50-60$ & 504 & 2 & 4 & 94 & $64.2 / 74.8$ & -8.6 \\
\hline 17 & $30-40$ & 498 & 6 & 0 & 94 & $66.8 / 80.6$ & -6.0 \\
\hline
\end{tabular}

Averaged noise parameters of track spans of a transport interchange are demonstrated in Figure 3 .

Sound power of noise of a spatial source is calculated by the formula (3) and equals:

$$
\begin{gathered}
L_{p}=72,8+10 \cdot \log \frac{604136}{1}=130,6 \quad d B A \\
S_{\text {tr.interchange }}=S_{\text {ellipse }}=\pi \cdot a \cdot b=3,14 \cdot 370 \cdot 260=302068 \mathrm{~m}^{2}
\end{gathered}
$$

The traffic interchange area is defined in a horizontal plane as an ellipse.

All calculated and measured values of noise levels in the calculated points marked in Figure 4 are collected in Table 4.

Table 4. Calculated and measured values of noise levels in the near-highway territories for the

\begin{tabular}{|c|c|c|c|c|c|c|c|}
\hline 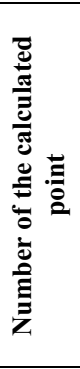 & 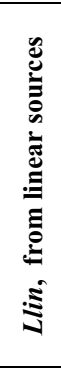 & 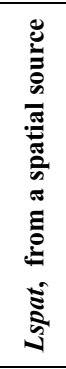 & 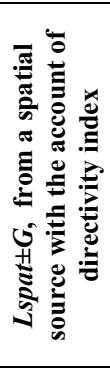 & 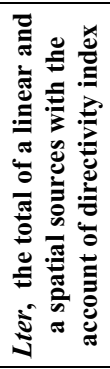 & 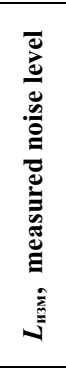 & 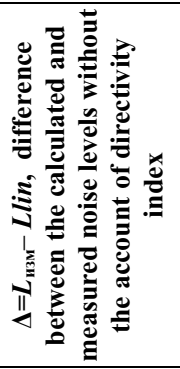 & 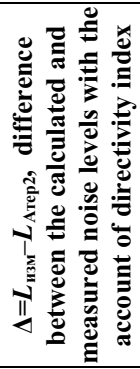 \\
\hline 1 & 2 & 3 & 4 & 5 & 6 & 7 & 8 \\
\hline 18 & 68.3 & 69.2 & 65.7 & 70.2 & 69.0 & 0.7 & -1.2 \\
\hline 19 & 57.1 & 75.0 & 70.0 & 70.2 & 67.8 & 10.7 & -2.4 \\
\hline 20 & 74.1 & 64.6 & 64.6 & 74.6 & 76.6 & 2.5 & 2.0 \\
\hline 21 & 55.3 & 73.0 & 63.7 & 64.3 & 64.3 & 9.0 & 0.0 \\
\hline 22 & 64.6 & 69.2 & 63.0 & 66.9 & 67.8 & 3.2 & 0.9 \\
\hline 23 & 68.6 & 82.1 & 78.7 & 79.1 & 80.8 & 12.2 & 1.7 \\
\hline 24 & 65.0 & 61.9 & 61.9 & 66.7 & 68.7 & 3.7 & 2.0 \\
\hline 25 & 69.6 & 73.3 & 69.9 & 72.8 & 68.2 & -1.4 & -4.6 \\
\hline 26 & 67.7 & 62.3 & 62.3 & 68.8 & 70.5 & 2.8 & 1.7 \\
\hline 27 & 66.5 & 72.3 & 66.3 & 69.4 & 64.2 & -2.3 & -5.2 \\
\hline 28 & 65.6 & 69.0 & 63.0 & 67.5 & 69.8 & 4.2 & 2.3 \\
\hline
\end{tabular}
calculated points, dBA. 
Table 4 demonstrates that when taking the integral sum for the calculated points 18,20 , $21,22,23,24,26$ the difference between the calculated and measured noise levels with the account of spatial source lies in the range of error of a sound level meter which is $\pm 1-2 \mathrm{dBA}$ (Table 4). When disregarding the transport interchange as a spatial noise source, the values obtained with the account of linear sources only mark down the results by 2 to $12 \mathrm{dBA}$.

For the calculated points located close to the edge of spatial noise source (points number 9, 25 and 27) noise level values are observed to be up to $5 \mathrm{dBA}$ higher. The results of other research in the field can be found in the paper $[9,10]$.

\section{Conclusion}

The paper presents classification of elements of road network and urban transport infrastructure which enables to apply the method for calculating noise pollution for a certain urban situation. The research shows that the model of acoustic sources of road network including not only linear sources (track spans), but also spatial sources (traffic interchanges and objects of transport infrastructure) realistically present noise parameters of all elements of urban road network. Error of the suggested method for noise level calculation in certain points with the combination of linear and spatial noise sources lies in the range of sound level meter error. This method is appropriate for predicting the noise parameters of built-up urban area. Noise profiles built on the basis of noise parameters of track spans only in certain cases show lower noise levels in the calculated points located in urban areas by up to $10 \mathrm{dBA}$.

Extension of this research requires detailed analysis of the reason for isolated errors in the obtained values for the calculated points located at the edge of acoustic center. The following hypothesis will be tested: while evaluating acoustic pollution objects of transport infrastructure shall be presented as spatial noise sources.

\section{References}

1. GOST 20444-2014 (ISO 1996-1:2003, NEQ; ISO 1996-2:2007, NEQ). Noise. Traffic flows. Methods of noise characteristic determination (Standartinform, Moscow, 2015) (in Russian)

2. GOST 23337-2014 (ISO 1996-1:2003, NEQ; ISO 1996-2:2007, NEQ). Noise. Methods of noise measurement in residential areas and in the rooms of residential, public and community buildings (Standartinform, Moscow, 2015) (in Russian)

3. SP 51.13330.2011. Noise protection. Revised edition of SNiP 23-03-2003 (Minregion Rossii, Moscow, 2010) (in Russian)

4. G.L. Osipov, V.E. Korobkov, A.A. Klimukhin, Zashhita ot shuma v gradostroitel'stve [Noise protection in urban development] (Strojizdat, Moscow, 1993) (in Russian)

5. G.L. Osipov, E.Yu. Yudin, G. Hubner, Snizhenie shuma v zdanijah i zhilyh rajonah [Reduction of noise in buildings and residential districts] (Strojizdat, Moscow, 1987) (in Russian)

6. P.I. Pospelov, Bor'ba s shumom na avtomobil'nyh dorogah [Noise control on highways] (Transport, Moscow, 1981) (in Russian)

7. P.I. Pospelov, V.I. Purkin, B.A. Shchit, Metodicheskie rekomendacii po zashhite ot transportnogo shuma territorij, prilegajushhih $k$ avtomobil'nym dorogam [Recommendations on traffic noise protection of the territories adjacent to highways], (Informavtodor Publ., Moscow, 2011)

8. A.A. Faktorovich, G.I. Postnikov. Zashhita gorodov ot transportnogo shuma [Protection of cities from traffic noise], 144 (Budivelnik, Kiev, 1982) 
9. S.N. Ovsiannikov, E.M. Kotova, Zhilishchnoe Stroitel'stvo [Housing construction], 6, $6(2013)$

10. T.S. Bolshanina, S.N. Ovsiannikov, BST - Bulletin of Construction Equipment 2.0, 6, 84 (2017) 